\title{
Alternative therapy of earth elements increases the chondroprotective effects of chondroitin sulfate in mice
}

\author{
M. Caraglia ${ }^{2,4}$, S. Beninati ${ }^{3}$, G. Giuberti ${ }^{2}$, \\ A.M. D'Alessandro ${ }^{2}$, A. Lentini ${ }^{3}$, \\ A. Abbruzzese ${ }^{2}$, G. Bove ${ }^{1}$, F. Landolfi ${ }^{1}$, \\ F. Rossi ${ }^{1}$, E. Lampa ${ }^{1}$ and M. Costantino ${ }^{1,5}$ \\ 'Specialty School of Medical Hydrology \\ Department of Experimental Medicine \\ Pharmacological Division \\ ${ }^{2}$ Department of Biochemistry and Biophysics \\ F. Cedrangolo II University of Naples \\ Via S. Maria di Costantinopoli \\ 16-80138-Naples, Italy \\ ${ }^{3}$ Department of Bidogy \\ II Tor Vergata University of Rome \\ Rome, Italy \\ ${ }^{4}$ National Cancer Institute \\ Fondazione G-Pascale of Naples, Italy. \\ ${ }^{5}$ Corresponding author: E-mail, maria.costantino@unina2.it
}

Accepted 5 June 2005

Abbreviations: CS, chondroitin sulfate; DAS, disruption of articular surface; DRT, duplication and rupture of the tidemark; FA fibrillar appearance; GAG, glycoso aminoglycans; HC, hypocellularity of chondrocytes; HE, haematoxylin; IGF-1, Insulin-like Growth Factor-1; $\mathrm{LI}$, labelling index; MLSS, moderate loss of safranin-0 staining; MMP, matrix metalloproteases; NO, nitric oxide; OA, ostecarthritis; PSR, picro sirius red; ROS, reactive axygen radicals; SLSS, severe loss of safranin-0 staining; TGF $\beta$, Transforming Growth Factor $\beta$

\section{Abstract}

The administration of mineral sulphur water is an alternative experimental approach for the treatment of rheumatic diseases, such as osteoarthritis (OA), that cause the degeneration of bone and cartilage and sufferance to the patients. Chondroitin sulfate (CS) is a symptomatic slow acting nutropeucital agent currently used in molecular therapy of OA. Therefore, we have studied the role and efficacy of the selective soil paste from the mineral sulphur enriched spring (mud)-therapy alone or in combination with CS in the treatment of OA. The study was performed on $40 \mathrm{C57}$ Black $6 \mathrm{~N}$ mice, an experimental model which spontaneously develop an osteoarthritic process. The animals were divided in $\mathbf{4}$ groups and were treated with the single agents or with the combination. After $\mathbf{3 0}$ days of treatment all the mice were sacrificed and right knees and blood were collected. It was found that $\mathrm{CS}$ determined a reduction of radiological and histological features of chondrodegeneration and that mud-therapy increased the effects of CS in the animal group treated with the combination. However, the effects of thermal therapy alone were not statistically significant. Since OA is characterized by an increase of the production of nitric oxide (NO) by chondrocytes in extracellular matrix with its consequent elevation in serum and synovial fluid, we have evaluated the effects of the treatments on serum NO levels. CS alone induced a statistically significant reduction of NO serum levels (90 $\pm 13 \mu \mathrm{M}$ vs $219 \pm$ $60 \mu \mathrm{M}$ of control group, $\boldsymbol{P}<0.05$ ) while mud-therapy alone induced a not stat istically significant reduction of serum NO $(170 \pm 62 \mu \mathrm{M}, P>0.05)$. However, the latter strongly potentiated the decrease of serum NO induced by $\mathrm{CS}(31 \pm 1.5 \mu \mathrm{M})$ with a high statistical significance if compared to both the control group ( $P$ $<0.01)$ and the CS-treated group $(P<0.05)$. In conclusion, this study demonstrates that mud-therapy with sulphur mineral water could represent an important phase of the therapeutic strategy of OA. This experimental strategy could integrate and potentiate the standard pharmacological tools. Moreover, we have set a valid experimental in vivo model for the study of the thermal effects on the development of OA.

Keywords: chondroitin sul fate; mud therapy; nitric oxide; ostheoarthritis; sulfur

\section{Introduction}

In recent years it is becoming more evident that the demand of a scientific validation of thermal therapy according to the modern experimental medicine methods in order to give scientific validation to the so-called Thermal Medicine is increasing. Until today the mechanisms of action and the activity of thermal therapy (mineral waters, mud baths and caves) in the control of rheumatic diseases are only partially known.

Osteoarthritis $(O A)$ is one of the diseases that can endow the therapeutical action of mud-therapy (Costantino et al., 1999; Costantino et al., 2001; Nappi et al., 2001; Flusser et al., 2002; Van Tubergen et al., 2002). The latter could be an additional strategy able to obtain 
a reduction of analgesic and/or non steroidal anti-inflammatory drugs consumption with a consequent amelioration of the quality of life and of the pharmaceutical costs.

On the basis of these considerations we have evaluated the chondroprotective action of a cycle of mudtherapy with sulphur mineral water alone or in combination with the chondroitin sulphate (CS), a currently used chondroprotective pharmacological agent. In addition, we have investigated if this therapy could induce adverse reactions and we have setted a useful in vivo experimental model for the study of the thermal therapy effects on the development of OA.

\section{Materials and Methods}

\section{In vivo studies}

The fine soil paste (mud) used for this study was the mineral sulphur water of Rosapepe Spa in Contursi (Salerno, Italy), derived from a mineral water that, for its chemical and physical characteristics, could be considered like bicarbonate alkaline sulphur mineral water (Table 1) (Marotta and Sica, 1929; Nappi et al., 2001). The experiments were performed on 40 Black $6 \mathrm{~N}$ Mice C57 of both sexes (not pregnant). In details, we have used 20 males, with mean weight of $30 \pm 0.5 \mathrm{~g}$ and 20 females with mean weight of $28 \pm 0.5 \mathrm{~g}$. The mice C57B $6 \mathrm{~N}$ are genetically altered in order to spontaneously develop a osteoarthritic process (Wilhelm et al., 1976). All the animals were maintained in fit conditions of nutrition and surrounding $\left(\mathrm{T}=21^{\circ} \mathrm{C}\right.$; humidity ratio $=55 \% 10$ ). European Union guidelines for the care of animals used for experimentation and other scientific purposes (Guideline 86/609/CCC and R.D. 223/88 B.O.E.) were as follows. After 30 days of treatment each mouse, after anesthesia with intraperitoneal injection of ketamine $(80 \mathrm{mg} / \mathrm{Kg})$, has been sacrificed and blood samples were collected in order to determine the levels of serum nitric oxide (NO) and their right knee joints were immediately extracted.

\section{Radiology}

Forty knee joints were radiographed with a microradiography unit (Faxitron; HewlettePackard, Rockville, MD) and high-detail film (Min-R; Eastman Kodak, Rochester, NY). Antero-posterior images from each specimen were obtained to further analyze them based on knee-joint OA criteria suggested by Shimizu et al. (1993).

\section{Tissue preparation}

Forty tibial epiphyses were fixed in $4 \%$ neutral buffered formalin for one day, decalcified in 10\% EDTA, sec-
Table 1. Chemical, physical and chemical-physical characteristics of the mineral water from Rosapepe terme.

\begin{tabular}{|c|c|}
\hline $\begin{array}{l}\text { General organologice } \\
\text { 1) Aspect = clear } \\
\text { 2) Favour = sulphure } \\
\text { 3) Taste = slightly sal }\end{array}$ & \\
\hline \multicolumn{2}{|c|}{ Microbiological test: bacteriologically pure } \\
\hline $\begin{array}{l}\text { Chemical-physical ch } \\
\text { 1) temperature of wa } \\
\text { 2) temperature of air } \\
\text { 3) Electric conducibil } \\
\text { 4) thickness = 1.002; } \\
\text { 5) } \mathrm{pH}=6.62\end{array}$ & $\begin{array}{l}\text { teristics: } \\
\text { the well }=+37.6^{\circ} \mathrm{C} \text {; } \\
\text { ide }=+4^{\circ} \mathrm{C} \text {; } \\
4.37 \mathrm{~m} / \mathrm{S} \text {; }\end{array}$ \\
\hline \multicolumn{2}{|c|}{ Chemical caracteristics: } \\
\hline \\
\hline \multicolumn{2}{|c|}{ 6) nitrites = traces; } \\
\hline \multicolumn{2}{|c|}{ Gas dissolved in 1 it of water. } \\
\hline \multicolumn{2}{|c|}{$\begin{array}{l}\text { 1) Carbonic anhydride at well }=1408.0 \mathrm{mg} / \\
\text { 2) sulphydric degree }=15.25 \mathrm{mg} /\end{array}$} \\
\hline \multicolumn{2}{|c|}{ Analysis of residue in mg/: } \\
\hline sodium & 420 \\
\hline potassium & 65 \\
\hline calcium & 525.32 \\
\hline magnesium & 115.57 \\
\hline lithium & 1.00 \\
\hline chlorine & 567.25 \\
\hline iron & 0.04 \\
\hline manganese & 0.13 \\
\hline fluorine & 0.18 \\
\hline barium & absent \\
\hline hydrogen carbonate & 2208.20 \\
\hline sulfites & 243 \\
\hline silica & 12.6 \\
\hline bromine & trace \\
\hline iodine & trace \\
\hline
\end{tabular}

Classification: IPER-THERMAL SULPHUR SODIC-CHLORIDE BICARBONATE ALKALINE MINERAL WATER

fioned in frontal planes, and then paraffin-embedded for further routine histopathology analysis with light microscopy. Serial frontal $5 \mathrm{~mm}$ sections were cut and placed on poly-L-lysine treated slides or on non-treated slides.

Histomorphology and histochemistry

From all samples haematoxylin (HE), alcian blue PAS, 
and safranin stains were performed in order to evaluate matrix abundance, cellularity and the content of glycosaminoglycans. Two sections of each specimen were stained with picro sirius red (PSR) (Junqueira et al., 1979) and analyzed by polarized light microscopy to evaluate the arrangement of collagen bundles. Articular cartilage was evaluated following Mankin et al.'s guidelines (Mankin et al., 1971). To evaluate articular cartilage four zones are defined: superficial, transitional, radial and calcification (Hunziker et al., 1992) within this tissue layer usually appear collapsed. The borderline between hyaline articular cartilage and the zone of calcified cartilage is called the tidemark.

\section{TUNEL}

For in situ visualization of apoptotic cells (APOC cells), the TUNEL method was performed following the method described by other authors (Gavrieli et al., 1992). In both immunohistochemistry and TUNEL stainings, positive cells were counted throughout three microscopic magnified fields $(40 x)$ of the central region of each articular cartilage. Only dark brown cells were considered as positive in these counts. The labeling in$\operatorname{dex}(\mathrm{LI})$ was calculated as the percentage of positive cells in each cartilage zone.

\section{Treatment schedule}

At the beginning of the experimental work the animals were divided into 4 experimental groups (A, B, C, and D). Each group consists of 10 animals, all including 5 males and 5 females (Figure 1):

The Agroup has been assumed as control group and have not subjected to any treatment. Control animals received similar application of distilled water to animals receiving mud-therapy and were injected with equal volume of $0.8 \% \mathrm{NaCl}$ solution to animals receiving $\mathrm{CS}$. The B group has been treated with a mud-therapy cycle with mineral sulphur water including 12 applications, administered once a day and lasting $15 \mathrm{~min}$ at the temperature of $40^{\circ} \mathrm{C}$; The $\mathrm{C}$ group was treated with orally administered CS at the dose of $0,3 \mathrm{mg} /$ day for 12 consecutive days; The D group was treated with a combination of mud-therapy with mineral sulphur water $+\mathrm{CS}$ for 12 consecutive days, as described above.

\section{NO spectrophotometric determination}

The determination of serum NO concentration, expressed in $\mu \mathrm{m}$, has been performed with an indirect method through the measure of serum concentrations of nitrates and nitrites. For NO determination the spectrophotometric reaction of Griess was used (Titheradge, 1998).

\section{Statistical analysis}

The mean and standard deviations of each variable were calculated. The comparison between groups was performed using the ManneWhitney U-test, which tests differences in distribution of ranks.

\section{Results}

\section{Radiographic examination}

Knee-joint space narrowing with marked sclerosis of subchondral bone and irregularity of joint surface were seen in $100 \%$ of the control group and in $80 \%$ of mice treated with only mud-therapy $(P>0.05)$. However, these alterations were observed only in $60 \%$ of mice treated with CS $(P<0.05)$ and in $30 \%(P<0.01)$ of mice treated with CS plus mud therapy (Figure 1). Thereafter, the treatment with mud therapy alone did not seem to prevent chondrodegenerative processes, but it increases chondroprotective effects of CS.

\section{Histological observations}

The control group showed progressive histopathological changes characteristic of developing OA. These included disruption of the articular surface (19.2\%), cleft $(63.5 \%)$, cloning $(80.8 \%)$, hypocellularity of chondrocytes $(16.2 \%)$, moderate $(50.6 \%)$ to severe $(40.4 \%)$ loss of safranin-O staining, and duplication and rupture of the tidemark $(54.5 \%$ ) (Table 2). In addition, a superficial layer with a fibrillar appearance was seen in $20 \%$ of the cases. Degenerative areas with decreased metachromasia and indicative of matrix breakdown were also observed. These morphological changes were not significantly reduced in the mice treated with mud ther-

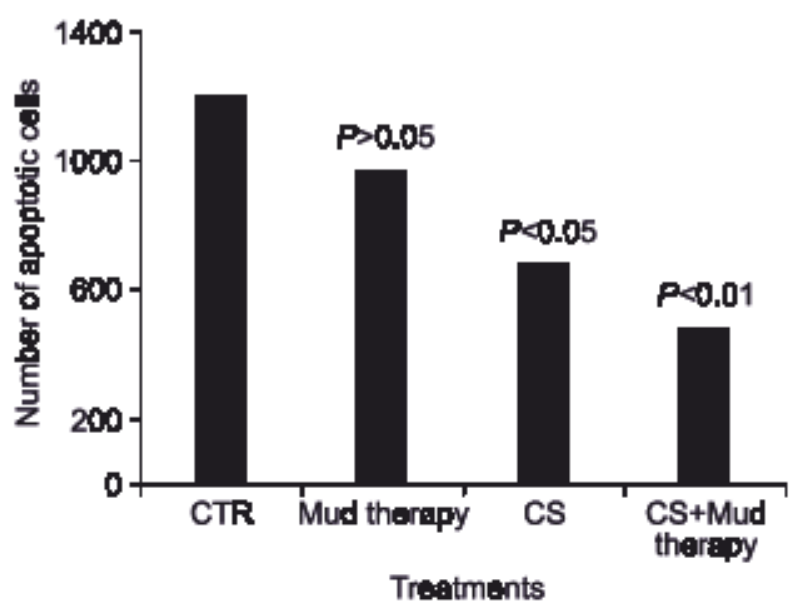

Figure 1. Effects on apopbsis after treatment with mud-sulphur therapy and/or pharmacological therapy with chondroitin sulfate in $\mathrm{C} 57$ black $6 \mathrm{~N}$ mice. 
Table 2. Histological modifications of the mice knee cartilage after the different treatments.

\begin{tabular}{lcccc}
\hline $\begin{array}{c}\text { Histological } \\
\text { changes }\end{array}$ & Control & Mud-therapy & CS & $\begin{array}{c}\text { CS + } \\
\text { Mud-therapy }\end{array}$ \\
\hline DAS & $19.2 \%$ & $15.1 \%$ & $10.1 \%^{*}$ & $7.6 \%^{* *}$ \\
Cleft & $63.5 \%$ & $53.1 \%$ & $40.1 \%^{*}$ & $30.2 \%^{*}$ \\
Cloning & $80.8 \%$ & $70.6 \%$ & $35.3 \%^{* *}$ & $20.9 \%^{* *}$ \\
HC & $16.2 \%$ & $15.6 \%$ & $10.1 \%^{*}$ & $5.6 \% * *$ \\
MLSS & $50.6 \%$ & $40.6 \%$ & $30.2 \%^{*}$ & $12.3 \%^{* *}$ \\
SLSS & $40.4 \%$ & $35.6 \%$ & $30.8 \%^{*}$ & $20.1 \%^{* *}$ \\
DRT & $54.5 \%$ & $53.2 \%$ & $30.9 \%^{*}$ & $20.1 \%^{* *}$ \\
FA & $20.0 \%$ & $18.0 \%$ & $10.0 \%^{*}$ & $5.0 \% * *$ \\
\hline
\end{tabular}

DAS, disruption of articular surface; $\mathrm{HC}$, mypocellularity of chondrocytes; MLSS, moderate loss of safranin-0 staining moderate; SLSS, severe bss of safranin-O staining; DRT, duplication and rupture of the tidemark; FA, fibrillar appearance.

"Significant stafisfical difference $(P<0.05)$; "Highly significant statistical difference $(P<0.01)$.

apy alone (see Table 2). The treatment with CS alone caused a statistically significan reduction of disruption of the articular surface $(10.1 \%)$, cleft $(40.1 \%)$, cloning $(35.3 \%)$, hypocellularity of chondrocytes $(10.1 \%)$, moderate $(30.2 \%)$ to severe $(30.8 \%)$ loss of safranin-O staining, and duplication and rupture of the tidemark $(30.9 \%)$ (Table 2). Moreover, the appearance of fibrillar structures was observed only in $10 \%$ of the tissue. The differences were statistically significant $(P<0.05)$ in almost all the cases and highly statistically significant in case of cloning $(P<0.01)$. In the mice treated with mud therapy plus CS the chondrodegenerative histological features were furtherly reduced. In fact, it was observed disruption of $7.6 \%$ articular surface in, $30.2 \%$ cleft, $20.9 \%$ cloning, $5.6 \%$ hypocellularity of chondrocytes, $12.3 \%$ moderate to $20.1 \%$ severe loss of safranin-O staining, and $20.1 \%$ duplication and rupture of the tidemark (Table 2). The statistical differences between CS plus mud therapy group and control group were highly statistically significant $(P<0.01)$. Therefore, mud therapy demonstrated to potentiate the chondroprotective effects of CS.

\section{Effects of mud and CS treatment on apoptotic labelling index}

In order to evaluate the effects of the treatments on the degeneration of cartilage of the mice we have detected the apoptotic index of chondrocytes of the cartilage of the sacrificed animals. In the cartilage of control group the apoptotic cells were $1205 \pm 189$ while the treatment with mud therapy showed statistically non-significant reduction of the apoptotic chondrocytes (974 \pm 236, $P<0.05$ ) (see Figure 1). On the other hand, CS induced a significant reduction of apoptotic chon-

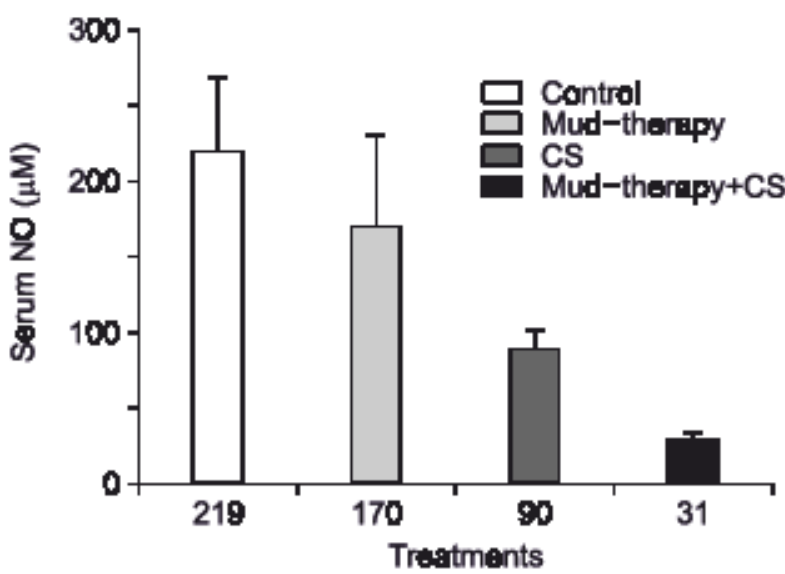

Figure 2. Eflects on serum concentrafion of NO after treatment with mud-sulphur therapy and/or pharmacological therapy with chondroitin sulfate in $\mathrm{C} 57$ black $6 \mathrm{~N}$ mice.

drocytes $(680 \pm 90, P<0.05)$ while the combined treatment furtherly decreased the apoptotic cell number $(480 \pm 70, P<0.01)$ (see Figure 1). These results suggested that the combined treatment could be active in arresting the degenerative potential of arthrosic cartilage through the decrease of the apoptotic index of cartilage cell compartment.

\section{Effects of mud and CS treatment on serum NO concentration}

Since NO generation by pro-inflammatoty cytokines has been involved in the pathogenesis of OA through the induction of chondrocyte apoptotsis and the consequent decrease of extracellular matrix production we have evaluated the effects of the treatments on NO serum levels. The treatment with $C S$ induced a significant $(P<0.05)$ reduction of serum NO concentration (C group: $90 \pm 13$ ) if compared with the control group (A group: $219 \pm 60$ ) (Figure 2). The combination between thermal treatment with mud-sulphur therapy and pharmacological therapy with chondroitin sulfate enhanced the reduction of NO serum concentration (D group: 31 \pm 1.5 ) (Figure 2). This difference was again statistically significant as compared with both controls $(P<$ $0.01)$ and CS-treatd mice $(P<0.05)$.

Finally, in the group of animals treated with mud sulphur therapy alone (B group: $170 \pm 62$ ) a reduction of the NO serum concentration was also recorded, as compared to the control group. However, this reduction was not statistically significant $(P>0.05)$ (Figure 2). These data appear to confirm the chondroprotective effect of CS and of CS + mud therapy and suggest a role for the inflammatory processes in the regulation of osteoarthrotic mechanisms in this experimental model. 


\section{Adverse effects}

During the experiments no adverse reactions or weight reduction were observed in the three groups of animals subjected to pharmacological and/or thermal treatment.

\section{Discussion}

$\mathrm{OA}$ is the most common degenerative osteoarticular disease characterized by the loss of the homeostasis between the anabolic and catabolic processes of bone tissue (Radine et al., 1986; Pelletier 1999). This alteration induces the degradation of the articular cartilage, synovium inflammation and the bone inspissation. All these pathological changes produce pain during articular movements, functional difficulty and articular stiffness. Data from literature (Cecchettin et al., 1995; Bellometti et al., 1996; Nguyen et al., 1997) seems to highlight the modulator role of mud-thermal treatment on the chondrocyte, a basic element of the cartilage, which reacts to the stimulus derived from the application of the mud thermal therapy through the activation of an anabolic response. In fact, it has been demonstrated that, during mud thermal therapy, a decrease of IL 1 and TNF- $\alpha$, both mediators of inflammation and of degenerative OA processes, is recorded. On the other hand, an increase of the serum concentration of ceruloplasmine and transferrin, both proteins involved in the circulating antioxidant defense system, is found. Other data (Nappi et al., 2001; Flusser et al., 2002) have demonstrated the protective role of mud thermal therapy on collagen and proteoglycans, thus avoiding the occurrence of degradative processes. It was also shown that mud-therapy has beneficial effects on several rheumatic diseases (Nguyen et al., 1997; Costantino et al., 1999; Costantino et al., 2001; Nappi et al., 2001; Flusser et al., 2002; Van Tubergen et al., 2002). Moreover, mud-therapy appeared to be able to prevent the progression of the cartilage degeneration through a chondroprotective effect in osteoarthritis (Chiodo et al., 1993; Anderson et al., 1999; Blanco 2000). Recently, it was found glycoso aminoglycans (GAG) have a chondroprotective effect through the modulation of the synthesis of cartilage. Among these molecules the CS, the most abundant cartilage GAG, is able to restore the metabolic homeostasis of the chondrocyte. In osteoarthritis, CS seems to ameliorate the clinic symptoms through its anabolic activity, through the increase of the synthesis of hyaluronic acid, glucosamine sulphate and type II collagen. Moreover, CS has an anti-catabolic action (block of the degradation of the extracellular matrix molecules), and a chondroprotective effect from the triggering of apoptotic processes induced by some toxic mediators like NO during OA. In fact, an increase of NO, tumour necrosis factor $\alpha$, interleukin 1, metalloproteases (MMP) and re- active oxygen radicals (ROS) is observed in OA, demonstrating the participation of these factors to the genesis and maintainance of degenerative processes in OA (Osborn et al., 1989; Moskowitz, 1993; Lotz et al., 1995; Blanco et al., 2000). NO is mainly produced by chondrocyte, induces apoptosis of the chondrocyte itself (Attisano et al., 1994; Borderie et al., 1999; Fukui et al., 2001; Purple et al., 2001), and inhibits the synthesis of components of cartilage matrix such as collagen type II and GAGs; NO, moreover, increases the acfivity of MMP, decreases the proliferative response to the Insulin-like Growth Factor-1 (IGF-1) and reduces the endogenous production of Transforming Growth Factor $\beta$ (TGF $\beta$ ), by chondrocyte, furtherly decreasing the synthesis of GAGs and of collagen fibers. Recent in vitro studies (Blanco et al., 2000) have demonstrated that CS blocks the synthesis of NO at the articular level.

On the basis of these considerations we have evaluated the probable in vivo antioxidant effect of a cycle of mud-therapy with sulphur mineral water versus a chondroprotective pharmacological agent, such as CS or the combination between the two different treatment modalities. We have designed an in vivo experimental model in mice that spontaneously develop chondrodegenerative processes and we have evaluated the feasibility of the treatment with mud-therapy in animals.

Our results have confirmed the antioxidant and potenfially chondroprotective action of the CS, as compared to the control group; however, the statistical difference was furtherly increased when mud-sulphur thermal therapy was combined to pharmacological therapy $(P$ $<0.01$ ). In fact, we have found that these treatments induced a decrease of radiological and histological features of chondrodegeneration and these effects were likely mediated by a significant reduction of the production of endogenous oxidant agents such as NO, a product of pro-inflammatory processes. On the other hand, mud therapy alone appeared to reduce the serum levels of NO as compared to CS-treated mice, but the difference was not statistically significant.

In conclusion, our data suggest that alternative therapy of old earth elements could be an important therapeutic tool in the treatment of OA. In fact, it could potenfiate the efficacy of the pharmacological therapy with $\mathrm{CS}$, thus inducing both more potent therapeutic effects and decreasing the required dose of CS. Moreover, our experimental models and tools could be useful to perform further investigations on the biological, molecular and pharmacological effects of this kind of therapy in vivo.

\section{References}

Anderson MA, Slater MR, Hammad TA. Results of a survey of small-animal practionners on the perceived dinical efficacy and safety of an oral nutraceutical. Preventive Veterinary Medicine 


\section{$1999 ; 38: 65-73$}

Attisano L, Wrana JL, Lopez-Casillas F, Massague J. TGFbeta receptors and actions. Biochimica and Biophysica Acta 1994;1222:71-80

Bellometti S, Cecchettin M, Lalli A, Galzigna L. Mud pack treatment increases serum antioxidant defenses in osteoarthrosic patients. Biomedidine and Phamacotherapy 1999; 50:5

Blanco FJ. Mecanismo de accion de condrocita sulfato a partir de estudios in vitro. Condroprotection 2000;6: 2-3

Borderie D, Hilliquin P, Hermvann A, Lemarechal H, Menkes CJ, Elindjian OG. Apoptosis induced bynitric oxide is associated with nuclear p53 protein expression in cultured osteorthritic synoviocytes. Osteoarthritis and Cartilage 1999;7:203-13

Cecchettin M, Bellometti S, Lalli A, Gaizigna L. Serum interleukin-1 changes in arthrosic patients after mud-pach treatment. Phys Rheab Kur Med 1995;92-3

Chiodo L, Maggiani G, Fioravanti A. La condroprotezione: it galattosaminoglucuronoglicansolfato nell'osteoartrosi. Rivista Italiana di Biologia Medica 1993;13:36-41

Costantino M, Lampa E. Efficacia a medio termine ed eventi indesiderati della terapia termale in campo reumatologico: preliminare studio clinico-epidemiologico. Igiene Moderna 2001; $116: 21-6$

Costantino M, Lampa E. Effetti a lungo termine della fangobalneoterapia sorgiva sulfurea: indagine epidemiologica. Medicina Clinica e Temale 2002;50-51:347-61

Costantino M, Rossi F, Lampa E. Attività anti-infiammatoria della fangoterapia: contributo sperimentale. Clinica Termale 1999;150(Suppl 1):141-2

Flusser D, Abu-shakra M, Friger M, Codish S, Sukenik S. Therapy with mud compresses for knee osteoarthritis: comparison of natural mud preparations with mineral-depleted mud. J Clin Rheumatol 2002;8:197-203

FukuiN, Purple CR, Sandell LJ. Cell biology of osteoarthritis the chondrocyte's response to injury. Osteoarthritis 2001;496-505

Gavrieli Y, Sherman Y, Ben-Sasson SA. Identification of programmed cell death in situ via specific labelling of nudear DNA fragmentation. Journal of Cell Biology 1992;119:493-501

Hunziker EB. Articular cartilage structure in humans and experimental animals. In: Kuettner KE, Schleyerbach R, Peyron JG, Hascall VC, Eds. Articular Cartilage and Osteoarthritis. New York: Raven Press 1992;183-99
Junqueira LC, Bignolas G, Brentani RR. Picrosirius staining plus polarization microscopy, a spedific method for collagen detection in tissue sections. Histochemistry J 1979;11:447-55

Lison L. Statistica applicata alla biologia sperimentale. Ed. Ambrosiana, 1989, Milano

Lotz $M$, et al. Cytokine regulation of chondrocyte functions. Journal of Rheumatology 1995;22:104-8

Mankin HJ, Dorfman H, Lippiello L, Zarins A. Biochemical and metabolic abnormalities in articular cartilage from osteo-arthritic human hips. II. Correlation of morphology with biochemical and metabolic data. J Bone Joint Surgery 1971;53A:523-37

Moskowitz RW. Rheumatic disease clinics of North America. Philadelphia W.B. Saunder ed.: 1993;7-16

Nappi G. Medidna e Clinica Termale. 2Ed. Selecta, Milano2001

Nguyen M, Revel M, Dougados M. Prolonged effects of 3 week therapy in a spa resort an lumbar spine, knee and hip ostecarthritis: follow-up after 6 months. A randomized controlled trial. Br J Rheumatol 1997;36:77-81

Osborn KD, et al. Growth factor stimulation of adult articular cartilage. J Orthopedic Research 1989;7:35-42

Pelletier JP. Pathophysiology of osteoarthritis. Osteoarthritis and Cartilage 1999;7:371-4

Purple CR, Sandell LJ. Cell biology osteoarthritis the chondrocyte's response to injury. Curr Rheumatol Reports 2001; 3:495-505

Radine EL, Rose RM. Role of subcondral bone in the inifation and progression of cartilage damage. Clinical Orthopedics 1986; 213:34-40

Shimizu M, Tsuji H, Matsui H, Katoh Y, Sano A. Morphometric analysis of subchondral bone of the tibial condyle in osteoarthrosis. Clinical Orthopedics 1993;293:229

Titheradge MA. The enzymatic measurement of nitrate and nitrite. In Titheradge MA, ed. Nitric oxide protocols. Totowa, New Jersey, USA: Humana Press Inc. 1998;83-91

Van Tubergen A, Van Der Linden S. A brief history of spa therapy. Annals of Rheumatic Diseases 2002;61:273-5

Wilhelm G, Faust R. Snitability of the $\mathrm{C} 57$ black mouse as an experimental animal for the study of skeletal changes due to aging, with special reference to osteoarthritis and its response to tribenoside. Pharmacology 1976;14:289 